\title{
Fixed point theorems for multivalued mappings in $G$-cone metric spaces
}

\author{
Akbar Azam* and Nayyar Mehmood
}

"Correspondence:

akbarazam@yahoo.com

Department of Mathematics,

COMSATS Institute of Information

Technology, Chak Shahzad,

Islamabad 44000, Pakistan

\begin{abstract}
We extend the idea of Hausdorff distance function in G-cone metric spaces and obtain fixed points of multivalued mappings in $G$-cone metric spaces.
\end{abstract}

MSC: $47 \mathrm{H} 10 ; 54 \mathrm{H} 25$

Keywords: G-cone metric space; non-normal cones; multivalued contraction; fixed points

\section{Introduction}

The main revolution in the existence theory of many linear and non-linear operators happened after the Banach contraction principle. After this principle many researchers put their efforts into studying the existence and solutions for nonlinear equations (algebraic, differential and integral), a system of linear (nonlinear) equations and convergence of many computational methods [1]. Banach contraction gave us many important theories like variational inequalities, optimization theory and many computational theories $[1,2]$. Due to wide spreading importance of Banach contraction, many authors generalized it in several directions [3-9]. Nadler [10] was first to present it in a multivalued case, and then many authors extended Nadler's multivalued contraction. One of the real generalizations of Nadler's theorem was given by Mizoguchi and Takahashi in the following way.

Theorem 1.1 [11] Let $(X, d)$ be a complete metric space, and let $T: X \rightarrow 2^{X}$ be a multivalued map such that $T x$ is a closed bounded subset of $X$ for all $x \in X$. If there exists a function $\varphi:(0, \infty) \rightarrow[0,1)$ such that $\lim \sup _{r \rightarrow t^{+}} \varphi(r)<1$ for all $t \in[0, \infty)$ and if

$$
H(T x, T y) \leq \varphi(d(x, y))(d(x, y)) \quad \text { for all } x, y(x \neq y) \in X,
$$

then $T$ has a fixed point in $X$.

Suzuki [12] proved that Mizoguchi and Takahashi's theorem is a real generalization of Nadler's theorem. Recently Huang and Zhang [13] introduced a cone metric space with a normal cone with a constant $K$, which is generalization of a metric space. After that Rezapour and Hamlbarani [14] generalized a cone metric space with a non-normal cone. Afterwards many researchers [15-24] have studied fixed point results in cone metric spaces. In [25] Mustafa et al. generalized the metric space and introduced the notion of G-metric space which recovered the flaws of Dhage's generalization $[26,27]$ of a metric space. Many

\section{Springer}

C 2013 Azam and Mehmood; licensee Springer. This is an Open Access article distributed under the terms of the Creative Commons Attribution License (http://creativecommons.org/licenses/by/2.0), which permits unrestricted use, distribution, and reproduction in any medium, provided the original work is properly cited. 
researchers proved many fixed point results using a G-metric space [28, 29]. Anchalee Kaewcharoen and Attapol Kaewkhao [28] and Nedal et al. [30] proved fixed point results for multivalued maps in G-metric spaces. In 2009, Beg et al. [31] introduced the notion of G-cone metric space and generalized some results. Chi-Ming Cheng [32] proved Nadlertype results in tvs $G$-cone metric spaces.

In 2011 Cho and Bae [33] generalized a Mizoguchi Takahashi-type theorem in a cone metric space. In the present paper, we introduce the notion of Hausdorff distance function on G-cone metric spaces and exploit it to study some fixed point results in G-cone metric spaces. Our result generalizes many results in literature.

\section{Preliminaries}

Let $E$ be a real Banach space. A subset $P$ of $E$ is called a cone if and only if:

(a) $P$ is closed, nonempty and $P \neq\{\theta\}$,

(b) $a, b \in R, a, b \geq 0, x, y \in P$ implies $a x+b y \in P$, more generally, if $a, b, c \in R, a, b, c \geq 0$, $x, y, z \in P \Longrightarrow a x+b y+c z \in P$

(c) $P \cap(-P)=\{\theta\}$.

Given a cone $P \subset E$, we define a partial ordering $\preccurlyeq$ with respect to $P$ by $x \preccurlyeq y$ if and only if $y-x \in P$.

A cone $P$ is called normal if there is a number $K>0$ such that for all $x, y \in E$

$$
\theta \preccurlyeq x \preccurlyeq y \quad \text { implies } \quad\|x\| \leq K\|y\| .
$$

The least positive number satisfying the above inequality is called the normal constant of $P$, while $x \ll y$ stands for $y-x \in \operatorname{int} P$ (interior of $P$ ), while $x \prec y$ means $x \preccurlyeq y$ and $x \neq y$.

Rezapour [14] proved that there are no normal cones with normal constants $K<1$ and for each $k>1$, there are cones with normal constants $K>1$.

Remark 2.1 [34] The results concerning fixed points and other results, in the case of cone spaces with non-normal solid cones, cannot be provided by reducing to metric spaces, because in this case neither of the conditions of Lemmas 1-4 in [13] hold. Further, the vector cone metric is not continuous in a general case, i.e., from $x_{n} \rightarrow x, y_{n} \rightarrow y$ it need not follow that $d\left(x_{n}, y_{n}\right) \rightarrow d(x, y)$.

For the case of non-normal cones, we have the following properties.

(PT1) If $u \preccurlyeq v$ and $v \ll w$, then $u \ll w$.

(PT2) If $u \ll v$ and $v \preccurlyeq w$, then $u \ll w$.

(PT3) If $u \ll v$ and $v \ll w$, then $u \ll w$.

(PT4) If $\theta \preccurlyeq u \ll c$ for each $c \in \operatorname{int} P$, then $u=\theta$.

(PT5) If $a \preccurlyeq b+c$ for each $c \in \operatorname{int} P$, then $a \preccurlyeq b$.

(PT6) If $E$ is a real Banach space with a cone $P$, and if $a \preccurlyeq \lambda a$, where $a \in P$ and $0 \leq \lambda<1$, then $a=\theta$.

(PT7) If $c \in \operatorname{int} P, a_{n} \in \mathbb{E}$ and $a_{n} \rightarrow \theta$, then there exists an $n_{0}$ such that, for all $n>n_{0}$, we have $a_{n} \ll c$.

In the following we shall always assume that the cone $P$ is solid and non-normal. 
Definition 2.1 [31] Let $X$ be a nonempty set. Suppose that a mapping $G: X \times X \times X \rightarrow E$ satisfies:

(G1) $G(x, y, z)=\theta$ if $x=y=z$,

(G2) $\theta \prec G(x, x, y)$, whenever $x \neq y$, for all $x, y \in X$,

(G3) $G(x, x, y) \preccurlyeq G(x, y, z)$, whenever $y \neq z$,

(G4) $G(x, y, z)=G(x, z, y)=G(y, x, z)=\cdots$ (symmetric in all three variables),

(G5) $G(x, y, z) \preccurlyeq G(x, a, a)+G(a, y, z)$ for all $x, y, z, a \in X$.

Then $G$ is called a generalized cone metric on $X$, and $X$ is called a generalized cone metric space or, more specifically, a $G$-cone metric space.

The concept of a $G$-cone metric space is more general than that of $G$-metric spaces and cone metric spaces (see [31]).

Definition 2.2 [31] A $G$-cone metric space $X$ is symmetric if $G(x, y, y)=G(y, x, x)$ for all $x, y \in X$.

Example 2.1 [31] Let $(X, d)$ be a cone metric space. Define $G: X \times X \times X \rightarrow E$ by $G(x, y, z)=d(x, y)+d(y, z)+d(z, x)$. Then $(X, G)$ is a $G$-cone metric space.

Proposition 2.1 [31] Let $X$ be a G-cone metric space, define $d_{G}: X \times X \rightarrow E$ by

$$
d_{G}(x, y)=G(x, y, y)+G(y, x, x) .
$$

Then $\left(X, d_{G}\right)$ is a cone metric space.

It can be noted that $G(x, y, y) \preccurlyeq \frac{2}{3} d_{G}(x, y)$. If $X$ is a symmetric $G$-cone metric space, then $d_{G}(x, y)=2 G(x, y, y)$ for all $x, y \in X$.

Definition 2.3 [31] Let $X$ be a G-cone metric space and let $\left\{x_{n}\right\}$ be a sequence in $X$.

We say that $\left\{x_{n}\right\}$ is:

(a) a Cauchy sequence if for every $c \in E$ with $\theta \ll c$, there is $N$ such that for all $n, m, l>N, G\left(x_{n}, x_{m}, x_{l}\right) \ll c$.

(b) a convergent sequence if for every $c$ in $E$ with $\theta \ll c$, there is $N$ such that for all $m, n>N, G\left(x_{m}, x_{n}, x\right) \ll c$ for some fixed $x$ in $X$. Here $x$ is called the limit of a sequence $\left\{x_{n}\right\}$ and is denoted by $\lim _{n \rightarrow \infty} x_{n}=x$ or $x_{n} \rightarrow x$ as $n \rightarrow \infty$.

A $G$-cone metric space $X$ is said to be complete if every Cauchy sequence in $X$ is convergent in $X$.

Proposition 2.2 [31] Let X be a G-cone metric space, then the following are equivalent.

(i) $\left\{x_{n}\right\}$ converges to $x$.

(ii) $G\left(x_{n}, x_{n}, x\right) \rightarrow \theta$ as $n \rightarrow \infty$.

(iii) $G\left(x_{n}, x, x\right) \rightarrow \theta$ as $n \rightarrow \infty$

(iv) $G\left(x_{m}, x_{n}, x\right) \rightarrow \theta$ as $m, n \rightarrow \infty$.

Lemma 2.1 [31] Let $\left\{x_{n}\right\}$ be a sequence in a G-cone metric space $X$. If $\left\{x_{n}\right\}$ converges to $x \in X$, then $G\left(x_{m}, x_{n}, x\right) \rightarrow \theta$ as $m, n \rightarrow \infty$. 
Lemma 2.2 [31] Let $\left\{x_{n}\right\}$ be a sequence in a G-cone metric space $X$ and $x \in X$. If $\left\{x_{n}\right\}$ converges to $x \in X$, then $\left\{x_{n}\right\}$ is a Cauchy sequence.

Lemma 2.3 [31] Let $\left\{x_{n}\right\}$ be a sequence in a G-cone metric space $X$. If $\left\{x_{n}\right\}$ is a Cauchy sequence in $X$, then $G\left(x_{m}, x_{n}, x_{l}\right) \rightarrow \theta$, as $m, n, l \rightarrow \infty$.

\section{Main result}

Denote by $N(X), B(X)$ and $C B(X)$ the set of nonempty, bounded, sequentially closed bounded subsets of $G$-cone metric spaces, respectively.

Let $(X, G)$ be a $G$-cone metric space. We define (see [33])

$$
s(p)=\{q \in E: p \preccurlyeq q\} \quad \text { for } q \in E,
$$

and

$$
s(a, B)=\bigcup_{b \in B} s\left(d_{G}(a, b)\right)=\bigcup_{b \in B}\left\{x \in E: d_{G}(a, b) \preccurlyeq x\right\} \quad \text { for } a \in X \text { and } B \in N(X) .
$$

For $A, B \in B(X)$, we define

$$
\begin{aligned}
& \hat{s}(A, B)=\bigcup_{a \in A, b \in B} s\left(d_{G}(a, b)\right), \\
& s(a, B, C)=s(a, B)+\hat{s}(B, C)+s(a, C)=\{u+v+w: u \in s(a, B), v \in \hat{s}(B, C), w \in s(a, C)\},
\end{aligned}
$$

and

$$
s(A, B, C)=\left(\bigcap_{a \in A} s(a, B, C)\right) \cap\left(\bigcap_{b \in B} s(b, A, C)\right) \cap\left(\bigcap_{c \in C} s(c, A, B)\right) .
$$

Lemma 3.1 Let $(X, G)$ be a G-cone metric space, let $P$ be a cone in a Banach space $E$.

(i) Let $p, q \in E$. If $p \preccurlyeq q$, then $s(q) \subset s(p)$.

(ii) Let $x \in X$ and $A \in N(X)$. If $0 \in s(x, A)$, then $x \in A$.

(iii) Let $q \in P$ and let $A, B, C \in B(X)$ and $a \in A$. If $q \in s(A, B, C)$, then $q \in s(a, B, C)$.

Remark 3.1 Recently, Kaewcharoen and Kaewkhao [28] (see also [30]) introduced the following concepts. Let $X$ be a $G$-metric space and let $C B(X)$ be the family of all nonempty closed bounded subsets of $X$. Let $H_{G}(\cdot, \cdot, \cdot)$ be the Hausdorff $G$-distance on $C B(X)$, i.e.,

$$
\begin{aligned}
& H_{G}(A, B, C)=\max \left\{\sup _{a \in A} G(a, B, C), \sup _{b \in B} G(b, A, C), \sup _{c \in C} G(c, A, B)\right\}, \\
& H_{d_{G}}(A, B)=\max \left\{\sup _{a \in A} d_{G}(a, B), \sup _{b \in B} d_{G}(b, A)\right\},
\end{aligned}
$$

where

$$
\begin{aligned}
& G(x, B, C)=d_{G}(x, B)+d_{G}(B, C)+d_{G}(x, C), \\
& d_{G}(x, B)=\inf \left\{d_{G}(x, y), y \in B\right\},
\end{aligned}
$$




$$
\begin{aligned}
& d_{G}(A, B)=\inf \left\{d_{G}(a, b), a \in A, b \in B\right\}, \\
& G(a, b, C)=\inf \{G(a, b, c), c \in C\} .
\end{aligned}
$$

The above expressions show a relation between $H_{G}$ and $H_{d_{G}}$. Moreover, note that if $(X, G)$ is a $G$-cone metric space, $E=R$, and $P=[0, \infty)$, then $(X, G)$ is a $G$-metric space. Also, for $A, B, C \in C B(X), H_{G}(A, B, C)=\inf s(A, B, C)$.

Remark 3.2 Let $(X, G)$ be a $G$-cone metric space. Then

(a) $\hat{s}(\{a\},\{b\})=s\left(d_{G}(a, b)\right)$ for $a, b \in X$.

(b) If $x \in s(a, B, B)$ then $x \in 2 s\left(d_{G}(a, b)\right)$.

Proof (a) By definition

$$
\begin{aligned}
\hat{s}(\{a\},\{b\}) & =\bigcup_{a \in\{a\}, b \in\{b\}} s\left(d_{G}(a, b)\right) \\
& =s\left(d_{G}(a, b)\right) .
\end{aligned}
$$

(b) Now let

$$
\begin{aligned}
& x \in s(a, B, B), \quad \text { then } \\
& x \in s(a, B, B)=s(a, B)+\hat{s}(B, B)+s(a, B) \\
& \Rightarrow \quad x \in 2 s(a, B)+\hat{s}(B, B) \\
& \Rightarrow \quad x \in 2 s\left(d_{G}(a, b)\right)+s(\theta) .
\end{aligned}
$$

Let $x=y+z$ for $y \in 2 s\left(d_{G}(a, b)\right)$ and $z \in s(\theta)$. Then by definition $\theta \preccurlyeq z$ and $2 d_{G}(a, b) \preccurlyeq y$, which implies $\theta+2 d_{G}(a, b) \preccurlyeq y+z=x$. Hence $2 d_{G}(a, b) \preccurlyeq x$, so $x \in 2 s\left(d_{G}(a, b)\right)$.

In the following theorem, we use the generalized Hausdorff distance on $G$-cone metric spaces to find fixed points of a multivalued mapping.

$\operatorname{Remark}$ 3.3 If $(X, G)$ is a $G$-metric space, then $\left(X, d_{G}\right)$ is a metric space, where

$$
d_{G}(x, y)=G(x, y, y)+G(y, x, x)
$$

It is noticed in [35] that in the symmetric case $((X, G)$ is symmetric), many fixed point theorems on $G$-metric spaces are particular cases of existing fixed point theorems in metric spaces. In these deductions, the fact $G(T x, T y, T y)+G(T y, T x, T x)=2 G(T x, T y, T y)=$ $d_{G}(T x, T y)$ is exploited for a single-valued mapping $T$ on $X$. Whereas in the case of multivalued mapping $T: X \rightarrow 2^{X}$ on a G-cone metric space,

$$
\begin{aligned}
s(T x, T y, T y) & =\left(\bigcap_{a \in T x} s(a, T y, T y)\right) \cap\left(\bigcap_{b \in T y} s(b, T x, T y)\right) \cap\left(\bigcap_{b \in T y} s(b, T x, T y)\right) \\
& =\left(\bigcap_{a \in T x} s(a, T y, T y)\right) \cap\left(\bigcap_{b \in T y} s(b, T x, T y)\right)
\end{aligned}
$$




$$
\begin{aligned}
& =\left(\bigcap_{a \in T x} 2 s(a, T y)\right) \cap\left(\bigcap_{b \in T y} s(b, T x)+\hat{s}(T x, T y)+s(b, T y)\right) \\
& \neq s(T y, T x, T x) .
\end{aligned}
$$

Therefore,

$$
\left(\bigcap_{a \in T x} s(a, T y)\right) \cap\left(\bigcap_{b \in T y} s(b, T x)\right) \neq s(T x, T y, T y)+s(T y, T x, T x)
$$

and even in a symmetric case, we cannot follow a similar technique to deduce G-cone metric multivalued fixed point results from similar results of metric spaces.

In a non-symmetric case, the authors [35] deduce some $G$-metric fixed point theorems from similar results of metric spaces by using the fact that if $(X, G)$ is a $G$-metric on $X$, then

$$
\delta(x, y)=\max \{G(x, y, y), G(y, x, x)\}
$$

is a metric on $X$. Whereas, in the case of a $G$-cone metric space, the expression $\max \{G(x, y, y), G(y, x, x)\}$ is meaningless as $G(x, y, y), G(y, x, x)$ are vectors, not essentially comparable, and we cannot find maximum of these elements. That is, $(X, \delta)$ may not be a cone metric space if $(X, G)$ is a $G$-cone metric space. In the explanation of this fact, we refer to Example 3.1 below, from [31]. Hence multivalued fixed point results on $G$-cone metric spaces cannot be deduced from similar fixed point theorems on metric spaces.

Example 3.1 [31] Let $X=\{a, b\}, E=R^{3}$,

$$
P=\{(x, y, z) \in E: x, y, z \geq 0\}
$$

Define $G: X \times X \times X \rightarrow E$ by

$$
\begin{aligned}
& G(a, a, a)=(0,0,0)=G(b, b, b), \\
& G(a, b, b)=(0,1,1)=G(b, a, b)=G(b, b, a), \\
& G(b, a, a)=(0,1,0)=G(a, b, a)=G(a, a, b) .
\end{aligned}
$$

Note that $\delta(a, b)=\max \{G(a, a, b), G(a, b, b)\}=\max \{(1,0,0),(0,1,1)\}$ has no meaning as discussed above.

Theorem 3.1 Let $(X, G)$ be a complete cone metric space, and let $T: X \longrightarrow C B(X)$ be a multivalued mapping. If there exists a function $\varphi: P \rightarrow[0,1)$ such that

$$
\lim \sup _{n \rightarrow \infty} \varphi\left(r_{n}\right)<1
$$

for any decreasing sequence $\left\{r_{n}\right\}$ in $P$, and if

$$
\varphi(G(x, y, z)) G(x, y, z) \in s(T x, T y, T z)
$$

for all $x, y, z \in X$, then $T$ has a fixed point in $X$. 
Proof Let $x_{0}$ be an arbitrary point in $X$ and $x_{1} \in T x_{0}$. From (1), we have

$$
\varphi\left(G\left(x_{0}, x_{1}, x_{1}\right)\right) G\left(x_{0}, x_{1}, x_{1}\right) \in s\left(T x_{0}, T x_{1}, T x_{1}\right) .
$$

Thus, by Lemma 3.1(iii), we get

$$
\varphi\left(G\left(x_{0}, x_{1}, x_{1}\right)\right) G\left(x_{0}, x_{1}, x_{1}\right) \in s\left(x_{1}, T x_{1}, T x_{1}\right) .
$$

By Remark 3.2, we can take $x_{2} \in T x_{1}$ such that

$$
\varphi\left(G\left(x_{0}, x_{1}, x_{1}\right)\right) G\left(x_{0}, x_{1}, x_{1}\right) \in 2 s\left(d_{G}\left(x_{1}, x_{2}\right)\right) .
$$

Thus,

$$
2 d_{G}\left(x_{1}, x_{2}\right) \preccurlyeq \varphi\left(G\left(x_{0}, x_{1}, x_{1}\right)\right) G\left(x_{0}, x_{1}, x_{1}\right) .
$$

Again, by (1), we have

$$
\varphi\left(G\left(x_{1}, x_{2}, x_{2}\right)\right) G\left(x_{1}, x_{2}, x_{2}\right) \in s\left(T x_{1}, T x_{2}, T x_{2}\right),
$$

and by Lemma 3.1(iii)

$$
\varphi\left(G\left(x_{1}, x_{2}, x_{2}\right)\right) G\left(x_{1}, x_{2}, x_{2}\right) \in s\left(x_{2}, T x_{2}, T x_{2}\right) .
$$

By Remark 3.2, we can take $x_{3} \in T x_{2}$ such that

$$
\varphi\left(G\left(x_{1}, x_{2}, x_{2}\right)\right) G\left(x_{1}, x_{2}, x_{2}\right) \in 2 s\left(d_{G}\left(x_{2}, x_{3}\right)\right)
$$

Thus,

$$
2 d_{G}\left(x_{2}, x_{3}\right) \preccurlyeq \varphi\left(G\left(x_{1}, x_{2}, x_{2}\right)\right) G\left(x_{1}, x_{2}, x_{2}\right) .
$$

It implies that

$$
\begin{aligned}
2 d_{G}\left(x_{2}, x_{3}\right) & \preccurlyeq \varphi\left(G\left(x_{1}, x_{2}, x_{2}\right)\right) G\left(x_{1}, x_{2}, x_{2}\right) \\
& \preccurlyeq \varphi\left(G\left(x_{1}, x_{2}, x_{2}\right)\right) G\left(x_{1}, x_{2}, x_{2}\right)+\varphi\left(G\left(x_{1}, x_{2}, x_{2}\right)\right) G\left(x_{2}, x_{1}, x_{1}\right) \\
& \preccurlyeq \varphi\left(G\left(x_{1}, x_{2}, x_{2}\right)\right)\left[G\left(x_{1}, x_{2}, x_{2}\right)+G\left(x_{2}, x_{1}, x_{1}\right)\right] \\
& =\varphi\left(G\left(x_{1}, x_{2}, x_{2}\right)\right) d_{G}\left(x_{1}, x_{2}\right) \\
& \Rightarrow \quad d_{G}\left(x_{2}, x_{3}\right) \preccurlyeq \frac{1}{2} \varphi\left(G\left(x_{1}, x_{2}, x_{2}\right)\right) d_{G}\left(x_{1}, x_{2}\right) .
\end{aligned}
$$

By induction we can construct a sequence $\left\{x_{n}\right\}$ in $X$ such that

$$
d_{G}\left(x_{n}, x_{n+1}\right) \preccurlyeq \frac{1}{2} \varphi\left(G\left(x_{n-1}, x_{n}, x_{n}\right)\right) d_{G}\left(x_{n-1}, x_{n}\right), \quad x_{n+1} \in T x_{n}, \text { for } n=1,2,3 \ldots
$$


Assume that $x_{n+1} \neq x_{n}$ for all $n \in N$. From (2) the sequence $\left\{d_{G}\left(x_{n}, x_{n+1}\right)\right\}_{n \in N}$ is a decreasing sequence in $P$. So, there exists $l \in(0,1)$ such that

$$
\lim \sup _{n \rightarrow \infty} \varphi\left(d_{G}\left(x_{n}, x_{n+1}\right)\right)=l .
$$

Thus, there exists $n_{0} \in N$ such that for all $n \geq n_{0}, \varphi\left(d_{G}\left(x_{n}, x_{n+1}\right)\right) \prec l_{0}$ for some $l_{0} \in(l, 1)$. Choose $n_{0}=1$, then we have

$$
\begin{aligned}
d_{G}\left(x_{n}, x_{n+1}\right) & \preccurlyeq \frac{1}{2} \varphi\left(d_{G}\left(x_{n-1}, x_{n}\right)\right) d_{G}\left(x_{n-1}, x_{n}\right) \\
& \prec l_{0} d_{G}\left(x_{n-1}, x_{n}\right) \\
& \prec\left(l_{0}\right)^{n} d_{G}\left(x_{0}, x_{1}\right) \quad \text { for all } n \geq 1 .
\end{aligned}
$$

Moreover, for $m>n \geq 1$, we have that

$$
d_{G}\left(x_{n}, x_{m}\right) \preccurlyeq \frac{\left(l_{0}\right)^{n}}{1-l_{0}} d_{G}\left(x_{0}, x_{1}\right) .
$$

According to (PT1) and (PT7), it follows that $\left\{x_{n}\right\}$ is a Cauchy sequence in $X$. By the completeness of $X$, there exists $v \in X$ such that $x_{n} \rightarrow v$. Assume $k_{1} \in N$ such that $d_{G}\left(x_{n}, v\right) \ll \frac{c}{2}$ for all $n \geq k_{1}$.

We now show that $v \in T v$. So, for $x_{n}, v \in X$ and by using (2), we have

$$
\varphi\left(G\left(x_{n}, v, v\right)\right) G\left(x_{n}, v, v\right) \in s\left(T x_{n}, T v, T v\right) .
$$

By Lemma 3.1(iii) we have

$$
\varphi\left(G\left(x_{n}, v, v\right)\right) G\left(x_{n}, v, v\right) \in s\left(x_{n+1}, T v, T v\right) .
$$

Thus there exists $u_{n} \in T v$ such that

$$
\varphi\left(G\left(x_{n}, v, v\right)\right) G\left(x_{n}, v, v\right) \in 2 s\left(d_{G}\left(x_{n+1}, u_{n}\right)\right) .
$$

It implies that

$$
\begin{aligned}
2 d_{G}\left(x_{n+1}, u_{n}\right) & \preccurlyeq \varphi\left(G\left(x_{n}, v, v\right)\right) G\left(x_{n}, v, v\right), \\
d_{G}\left(x_{n+1}, u_{n}\right) & \preccurlyeq \frac{1}{2} \varphi\left(G\left(x_{n}, v, v\right)\right) G\left(x_{n}, v, v\right) \\
& \preccurlyeq \varphi\left(G\left(x_{n}, v, v\right)\right)\left[G\left(x_{n}, v, v\right)+G\left(x_{n}, x_{n}, v\right)\right] \\
& =\varphi\left(G\left(x_{n}, v, v\right)\right) d_{G}\left(x_{n}, v\right) .
\end{aligned}
$$

So

$$
d_{G}\left(x_{n+1}, u_{n}\right) \preccurlyeq \varphi\left(G\left(x_{n}, v, v\right)\right) d_{G}\left(x_{n}, v\right) .
$$


Now consider

$$
\begin{aligned}
d_{G}\left(v, u_{n}\right) & \preccurlyeq d_{G}\left(x_{n+1}, v\right)+d_{G}\left(x_{n+1}, u_{n}\right) \\
& \preccurlyeq d_{G}\left(x_{n+1}, v\right)+\varphi\left(G\left(x_{n}, v, v\right)\right) d_{G}\left(x_{n}, v\right) \quad \text { by using (3) } \\
& \prec d_{G}\left(x_{n+1}, v\right)+d_{G}\left(x_{n}, v\right), \\
d_{G}\left(v, u_{n}\right) & \ll \frac{c}{2}+\frac{c}{2}=c, \quad \text { for all } n \geq k_{1} .
\end{aligned}
$$

Therefore $\lim _{n \rightarrow \infty} u_{n}=v$. Since $T v$ is closed, so $v \in T v$.

The next corollary is Nadler's multivalued contraction theorem in a G-cone metric space.

Corollary 3.1 Let $(X, G)$ be a complete G-cone metric space, and let $T: X \rightarrow C B(X)$ be a multivalued mapping. If there exists a constant $k \in[0,1)$ such that

$$
k G(x, y, z) \in s(T x, T y, T z)
$$

for all $x, y, z \in X$, then $T$ has a fixed point in $X$.

By Remark 3.1, we have the following results of [30].

Corollary 3.2 [30] Let $(X, G)$ be a complete G-metric space, and let $T: X \rightarrow C B(X)$ be a multivalued mapping. If there exists a function $\varphi:[0,+\infty) \rightarrow[0,1)$ such that

$$
\lim \sup _{r \rightarrow t^{+}} \varphi(r)<1
$$

for any $t \geq 0$, and if

$$
H_{G}(T x, T y, T z) \leq \varphi(G(x, y, z)) G(x, y, z)
$$

for all $x, y, z \in X$, then $T$ has a fixed point in $X$.

Corollary 3.3 [30] Let $(X, G)$ be a complete G-metric space, and let $T: X \longrightarrow C B(X)$ be a multivalued mapping. If there exists a constant $k \in[0,1)$ such that

$$
H_{G}(T x, T y, T z) \leq k G(x, y, z)
$$

for all $x, y, z \in X$, then $T$ has a fixed point in $X$.

In the following we formulate an illustrative example regarding our main theorem.

Example 3.2 Let $X=[0,1], E=C[0,1]$ be endowed with the strongly locally convex topology $\tau\left(E, E^{*}\right)$, and let $P=\{x \in E: 0 \leq x(t), t \in[0,1]\}$. Then the cone is $\tau\left(E, E^{*}\right)$-solid, and non-normal with respect to the topology $\tau\left(E, E^{*}\right)$. Define $G: X \times X \times X \rightarrow E$ by

$$
G(x, y, z)(t)=\operatorname{Max}\{|x-y|,|y-z|,|x-z|\} e^{t} .
$$

Then $G$ is a $G$-cone metric on $X$. 
Consider a mapping $T: X \rightarrow C B(X)$ defined by

$$
T x=\left[0, \frac{1}{10} x\right]
$$

Let $\varphi(t)=\frac{1}{5}$ for all $t \in P$. The contractive condition of the main theorem is trivial for the case when $x=y=z=0$. Suppose, without any loss of generality, that all $x, y$ and $z$ are nonzero and $x<y<z$. Then

$$
G(x, y, z)=|x-z| e^{t}
$$

and

$$
d_{G}(x, y)=2|x-y| e^{t} .
$$

Now

$$
\begin{aligned}
& s(x, T y)= \begin{cases}0 & \text { if } x \leq \frac{y}{10} \\
\left|x-\frac{y}{10}\right| e^{t} & \text { if } x>\frac{y}{10}\end{cases} \\
& s(y, T z)= \begin{cases}0 & \text { if } y \leq \frac{z}{10} \\
\left|y-\frac{z}{10}\right| e^{t} & \text { if } y>\frac{z}{10}\end{cases}
\end{aligned}
$$

For $s(x, T y)=0=s(y, T z)$, we have

$$
\begin{aligned}
& s(x, T y, T z)=s(0), \\
& \bigcap_{y \in T y} s(y, T x, T z)=s\left(2\left|\frac{y}{10}-\frac{x}{10}\right| e^{t}\right),
\end{aligned}
$$

and

$$
\bigcap_{z \in T z} s(z, T x, T y)=s\left(2\left|\frac{z}{10}-\frac{x}{10}-\frac{y}{10}\right| e^{t}\right) .
$$

Thus

$$
s(T x, T y, T z)=(s(0)) \cap\left(s\left(2\left|\frac{y}{10}-\frac{x}{10}\right| e^{t}\right)\right) \cap\left(s\left(2\left|\frac{z}{10}-\frac{x}{10}-\frac{y}{10}\right| e^{t}\right)\right) .
$$

Now

$$
\begin{aligned}
& \text { If } s(T x, T y, T z)=s\left(2\left|\frac{z}{10}-\frac{x}{10}-\frac{y}{10}\right| e^{t}\right), \quad \text { then } \\
& \begin{aligned}
2\left|\frac{z}{10}-\frac{x}{10}-\frac{y}{10}\right| e^{t} & \leq 2\left|\frac{z}{10}-\frac{x}{10}\right| e^{t}, \quad \text { for } t \in[0,1] \\
& =\frac{1}{5}|z-x| e^{t}=\frac{1}{5} \operatorname{Max}\{|x-y|,|y-z|,|x-z|\} e^{t} \\
& =\frac{1}{5} G(x, y, z) ;
\end{aligned}
\end{aligned}
$$




$$
\begin{aligned}
& \text { If } s(T x, T y, T z) \\
& =s\left(2\left|\frac{y}{10}-\frac{x}{10}\right| e^{t}\right), \quad \text { then } \\
& \begin{aligned}
2\left|\frac{y}{10}-\frac{x}{10}\right| e^{t} & \leq 2\left|\frac{z}{10}-\frac{x}{10}\right| e^{t}, \quad \text { for } t \in[0,1] \\
& =\frac{1}{5}|z-x| e^{t}=\frac{1}{5} \operatorname{Max}\{|x-y|,|y-z|,|x-z|\} e^{t} \\
& =\frac{1}{5} G(x, y, z) .
\end{aligned}
\end{aligned}
$$

Hence,

$$
\frac{1}{5} G(x, y, z) \in s(T x, T y, T z)
$$

All the assumptions of Theorem 3.1 also hold for other possible values of $s(x, T y)$ and $s(y, T z)$ to obtain $0 \in T 0$.

\section{Competing interests}

The authors declare that they have no competing interests.

\section{Authors' contributions}

Both authors read and approved the final manuscript.

\section{Acknowledgements}

We are very grateful to the editor and anonymous referees for their valuable and constructive comments that helped us very much in improving the paper.

\section{Received: 11 December 2012 Accepted: 15 July 2013 Published: 29 July 2013}

\section{References}

1. Moore, RE, Cloud, MJ: Computational Functional Analysis, 2nd edn. Ellis Horwood Series in Mathematics and Its Applications. Woodhead Publishing, Cambridge (2007)

2. Noor, A: Principles of Variational Inequalities. Lambert Academic Publishing, Saarbrücken (2009)

3. Abbas, M, Hussain, N, Rhoades, BE: Coincidence point theorems for multivalued $f$-weak contraction mappings and applications. RACSAM Rev. R. Acad. Cienc. Exactas Fis. Nat. Ser. a Mat. 105(2), 261-272 (2011)

4. Agarwal, RP, O'Regan, DO, Shahzad, N: Fixed point theorems for generalized contractive maps of Mei-Keeler type. Math. Nachr. 276, 3-12 (2004)

5. Agarwal, RP, Karapinar, E: Remarks on some coupled fixed point theorems in G-metric spaces. Fixed Point Theory Appl. 2013, Article ID 10 (2013). doi:10.1186/1687-1812-2013-2

6. Azam, A, Arshad, M, Beg, I: Existence of fixed points in complete cone metric spaces. Int. J. Mod. Math. 5(1), 91-99 (2010)

7. Hussain, N, Abbas, M: Common fixed point results for two new classes of hybrid pairs in symmetric spaces. Appl. Math. Comput. 218, 542-547 (2011)

8. Hussain, N, Karapinar, E, Salimi, P, Vetro, P: Fixed point results for $G^{m}$-Meir-Keeler contractive and $G-(\alpha, \psi)$-Meir-Keeler contractive mappings. Fixed Point Theory Appl. 2013, Article ID 34 (2013)

9. Wang, T: Fixed point theorems and fixed point stability for multivalued mappings on metric spaces. Nanjing Daxue Xuebao Shuxue Bannian Kan 6, 16-23 (1989)

10. Nadler, SB Jr: Multi-valued contraction mappings. Pac. J. Math. 30, 475-478 (1969)

11. Mizoguchi, N, Takahashi, W: Fixed point theorems for multi-valued mappings on complete metric spaces. J. Math. Anal. Appl. 141, 177-188 (1989)

12. Suzuki, T: Mizoguchi-Takahashi's fixed point theorem is a real generalization of Nadler's. J. Math. Anal. Appl. 340(1), 752-755 (2008)

13. Huang, LG, Zhang, $X$ : Cone metric spaces and fixed point theorems of contractive mappings. J. Math. Anal. Appl. 332(2), 1468-1476 (2007). doi:10.1016/j.jmaa.2005.03.087

14. Rezapour, S, Hamlbarani, R: Some notes on the paper 'Cone metric spaces and fixed point theorems of contractive mappings.' J. Math. Anal. Appl. 345, 719-724 (2008)

15. Abbas, M, Rhoades, BE: Fixed and periodic point results in cone metric spaces. Appl. Math. Lett. 22(4), $511-515$ (2009)

16. Azam, A, Arshad, M, Beg, I: Common fixed points of two maps in cone metric spaces. Rend. Circ. Mat. Palermo 57, 433-441 (2008)

17. Bari, CD, Vetro, P: $\phi$-pairs and common fixed points in cone metric spaces. Rend. Circ. Mat. Palermo 57, 279-285 (2008)

18. Bari, CD, Vetro, P: Weakly $\phi$-pairs and common fixed points in cone metric spaces. Rend. Circ. Mat. Palermo 58, 125-132 (2009)

19. Branciari, A: A fixed point theorem for mappings satisfying a general contractive condition of integral type. Int. J. Math. Math. Sci. 29, 531-536 (2002) 
20. Cho, SH, Bae, JS: Fixed point theorems for multivalued contractive mappings and multivalued Caristi type mappings in cone metric spaces. Fixed Point Theory Appl. 2012, Article ID 133 (2012). doi:10.1186/1687-1812-2011-87

21. Du, WS: A note on cone metric fixed point theory and its equivalence. Nonlinear Anal., Theory Methods Appl. 72(5), 2259-2261 (2010)

22. Kadelburg, Z, Radenovič, S: Some results on set-valued contractions in abstract metric spaces. Comput. Math. Appl. $62,342-350(2011)$

23. Klim, D, Wardowski, D: Dynamic processes and fixed points of set-valued nonlinear contractions in cone metric spaces. Nonlinear Anal. 71, 5170-5175 (2009)

24. Shatanawi, W: Some common coupled fixed point results in cone metric spaces. Int. J. Math. Anal. 4, 2381-2388 (2010)

25. Mustafa, Z, Sims, B: A new approach to generalized metric spaces. J. Nonlinear Convex Anal. 7(2), 289-297 (2006)

26. Dhage, BC: Generalized metric space and mapping with fixed point. Bull. Calcutta Math. Soc. 84, 329-336 (1992)

27. Dhage, BC: Generalized metric space and topological structure. I. An. Stiint. Univ. Al. I. Cuza lasi. Mat. (N.S.) 46(1), 3-24 (2000)

28. Kaewcharoen, A, Kaewkhao, A: Common fixed points for single-valued and multi-valued mappings in G-metric spaces. Int. J. Math. Anal. 5(36), 1775-1790 (2011)

29. Mustafa, Z, Sims, B: Some remarks concerning D-metric spaces. In: Proc. Int. Conf. on Fixed Point Theory and Appl. pp. 189-198. Valencia, Spain, July 2003 (2003)

30. Nedal, T, Hassen, A, Karapinar, E, Shatanawi, W: Common fixed points for single-valued and multi-valued maps satisfying a generalized contraction in G-metric spaces. Fixed Point Theory Appl. 2012, Article ID 48 (2012)

31. Beg, I, Abbas, M, Nazir, T: Generalized cone metric spaces. J. Nonlinear Sci. Appl. 3(1), 21-31 (2010)

32. Chen, CM: On set-valued contractions of Nadler type in tvs-G-cone metric spaces. Fixed Point Theory Appl. 2012, Article ID 52 (2012). doi:10.1186/1687-1812-2012-52

33. Cho, SH, Bae, JS: Fixed point theorems for multi-valued maps in cone metric spaces. Fixed Point Theory Appl. 2011, Article ID 87 (2011). doi:10.1186/1687-1812-2011-87

34. Janković, S, Kadelburg, Z, Radenović, S: On cone metric spaces: a survey. Nonlinear Anal. 74, 2591-2601 (2011)

35. Jlelli, M, Samet, B: Remarks on G-metric spaces and fixed point theorems. Fixed Point Theory Appl. 2012, Article ID $210(2012)$

doi:10.1186/1029-242X-2013-354

Cite this article as: Azam and Mehmood: Fixed point theorems for multivalued mappings in G-cone metric spaces. Journal of Inequalities and Applications 2013 2013:354.

\section{Submit your manuscript to a SpringerOpen ${ }^{\circ}$ journal and benefit from:}

- Convenient online submission

- Rigorous peer review

- Immediate publication on acceptance

- Open access: articles freely available online

- High visibility within the field

- Retaining the copyright to your article 